\title{
Nest site selection by Black-necked Crane Grus nigricollis in the Ruoergai Wetland, China
}

\author{
HEQI WU, KE ZHA, MING ZHANG and XIAOJUN YANG
}

\begin{abstract}
Summary
From 5 May 2003 to early June 2005, nest site selection of Black-necked Cranes Grus nigricollis was studied at the Ruoergai Wetland Nature Reserve (RWNR), an important breeding area for the species in China. Results showed that the crane nests only in wetland environments, including lake, swamp and river microhabitats. However, the bird showed different selection patterns in these microhabitats. According to the Ivelev selectivity index (S.I.), cranes preferred lakes and avoided swampy areas, while they used river areas in proportion to their availability. Factors associated with the selection of nest sites included water body size, distance to water, water depth and the level of nest concealment. Nest size was a function of the microhabitat used for nesting; nests were largest in lakes, and similarly-sized in swamp and river habitats. A certain water depth was a prerequisite for nest site selection $($ mean $=31.1 \mathrm{~cm})$, but no differences were found among different microhabitats. Compared with nests found in Qinghai, Tibet, and Ladakh, nests in Ruoergai Wetland were smaller, but water depth near nesting sites was higher (mean = $31.1 \mathrm{~cm}$ vs $18.2 \mathrm{~cm}$ ). Different plant communities, climate and disturbance are likely to be related to these differences. Conservation efforts should focus on the protection of existing lakes, minimizing disturbance impacts and maintaining small patches (i.e. $100 \mathrm{~m}^{2}$ water bodies) of swamp areas as important buffer zones. In the future, restoration of wetlands to decrease fragmentation, and reduction of habitat degradation are advocated for effective conservation of this species.
\end{abstract}

\section{Introduction}

Because of the remoteness of its breeding and wintering areas, which were also politically inaccessible until the past few decades, ecological information on the Black-necked Crane Grus nigricollis is sparse and it is the least well understood member of the crane family, a situation that limits conservation efforts (Meine and Archibald 1996). Prior to the late 1970s, reports on the species came from several surveys on the Qinghai-Tibet Plateau (Dresser 1906, Stone 1933, Dolan 1939, Vaurie 1972, Archibald and Oesting 1981) but little was known about the status and ecology of the bird. From 1979, some nests were measured and nest site habitats were described (Dwyer et al. 1992, Scott 1993, Li and Ma 1989, Pfister 1998). Anthropogenic pressures, such as loss and deterioration of habitat, are considered as major threats to the species in both wintering range and breeding areas (Bishop 1996). The species is listed as 'Vulnerable' on the IUCN Red List (BirdLife International 2008), and is included on Appendix I of CITES (UNEP-WCMC 2003). Black-necked Cranes spend the winter in three regions: NE Yunnan and NW Guizhou provinces (Eastern Population, EP); NW Yunnan (Central Population, CP); and S Tibet and Bhutan (Western Population, WP) (Li \& Yang 2003). The birds breed on the Qinghai-Tibet Plateau, mainly in China. The only breeding population outside China $(<20$ pairs) is in Ladakh, India (Birdlife International 2001). Breeding birds select marshy grassland, small ponds in sedge meadows, lakeshore marshes, and riparian marshes along secondary channels or small streams as 
nest sites (Li 1987). Preferred foraging habitats include shallow marshes, lakeshores, small streams, and upland pastures (Scott 1993). Roots and tubers, insects, snails, shrimps, fish, small birds and rodents are included in the diet (Bishop 1996). Habitat loss and disturbance are the main threats to the species. Egg collecting, feral dogs and intense grazing pressure are also considered important threats (Scott 1993). For example, in Ruoergai Wetland, an important breeding area in northern Sichuan province, human activities (drainage, peat mining for fuel, and conversion to grassland) have degraded the wetland since the 1960s. But the breeding status and ecology, especially nest site selection, have not been studied since the first large area survey in 1993 (Scott 1993).

Understanding nest site selection characteristics is imperative for making conservation decisions on bird habitat, and managers usually lack such knowledge (Bock 1997, Caughley 1994, Willson and Gende 2000). Previous work in primary breeding areas, such as Qinghai province, Tibet and Ladakh, have focused on nest measurements and provided useful clues to nest site selection. However, compared with these areas, habitats in Ruoergai Wetland face much higher development pressure. Thus, comparison of nest characteristics in primary areas with those in developed areas might promote understanding of how birds adapt to a changing environment and inform effective management.

\section{Methods}

\section{Study Site}

With an area of $19,600 \mathrm{~km}^{2}$ and average elevation of 3,450 $\mathrm{m}$ a.s.l., the Ruoergai Wetland $\left(33^{\circ} 25^{\prime}-34^{\circ} 25^{\prime} \mathrm{N}, 102^{\circ} 29^{\prime}-102^{\circ} 59^{\prime} \mathrm{E}\right)$ is located in the upper Yellow River valley on the eastern Tibetan Plateau and straddles the boundary between the provinces of Sichuan and Gansu. Lakes, marshes and rivers form the core area of this internationally important wetland (Scott 1993), which consists of bogs, fens, wet meadows and shallow water, interspersed with low hills and sub-alpine meadows (Yan and $\mathrm{Wu} 2005$ ) and is surrounded by high mountains (4,000 $\mathrm{m}$ a.s.l.). Annual precipitation in the region ranges from 560 to $860 \mathrm{~mm}$ and annual average temperatures are between $0.6-1.5^{\circ} \mathrm{C}$. The wetland is considered both nationally and globally important for biodiversity conservation by the Biodiversity Review of China and the China Biodiversity Conservation Action Plan (McNamee 2003). Ruoergai Wetland Nature Reserve (RWNR) with an area of $1,666 \mathrm{~km}^{2}$ was established in 1998 to conserve the breeding habitat of Black-necked Cranes and other waterbirds, as well as to protect the vulnerable plateau wetland ecosystem.

After 900 cranes were estimated to inhabit the wetland, Scott (1993) considered it the most important breeding and summering area for the species. Recovery of banded Black-necked Cranes showed that birds wintered in Guizhou (Wu et al. 1993) and Yunnan Province (Yang et al. 2005). Local Tibetan pastoralists camp on the plains during the summer months (June-August) and return to permanent villages along the edge of the hills for the winter (Scott 1993). The total number of livestock exceeds one million (Sichuan Forestry Survey and Planning Institute 1997). Peat mining, drainage and overgrazing by domestic livestock have decreased the area of wetland by more than 200,000 ha compared with the 1960s (Sichuan Forestry Survey and Planning Institute 1997). To conserve the wetland for sustainable use, local government adjusted grazing policy by fencing private grasslands ( $Y a n$ and $\mathrm{Wu}$ 2005). Fences prevent livestock access to private grassland, but Black-necked Cranes are also affected by this policy change because they have to increase search time by flying from one patch to another (Yang et al. 2007). Disturbance to breeding cranes includes egg collection by people, egg depredation by Red Fox (Vulpes vulpes) and feral dogs, and disturbance to nesting cranes by livestock. Some parts of the wetland, especially the lake side, were selected by the local government for economic development as a tourist destination. Several roads and artificial establishments have been built near the wetland. Roads, buildings and large areas of fences have fragmented the wetland and meadows. 


\section{Data collection}

During the breeding season, breeding cranes are isolated in their territories, while non-breeding birds form flocks and wander in summering areas (Meine and Archibald 1996). Breeding cranes maintain their territory mainly by ritualization threats (Li and Ma 1989), or by pecking and chasing invaders ( $\mathrm{Li}$ 1996). Researchers have used observations of territorial behaviour to locate nest sites in several breeding crane studies (Borad et al. 2001; Yang et al. 2007). We drove a vehicle at 15-20 $\mathrm{km} \mathrm{h}^{-1}$ and scanned both sides of the road to locate incubating cranes and nests, similar to the method used by Borad et al. (2001) in a study of Sarus Cranes G. antigone. The open and flat environment made it easy to locate crane territories and nests. Except in Qinghai Province $\left(4 \mathrm{~km}^{2}\right)$, breeding territories of Black-necked Crane average $<2 \mathrm{~km}^{2}$ (Li and Ma 1989, Li and Zhou 1985, Pfister 1998), which made the survey more effective in a short period.

From 2003 to 2005, we surveyed nests in RWNR from May to late June. In 2003, we found the first nest in early May and the primary nest building time was late May (Yang et al. 2007). Three steps were used to determine nest sites and locate nests: 1 ) we scanned both sides of the roads with $8 \times 42$ binoculars, including meadow, lake, swamp and river habitats, to locate paired and non-breeding cranes; 2) We observed the behaviour of paired birds for $10-20$ minutes to determine whether or not the site was a nest site (i.e. cranes return following the disturbance) or a feeding site (i.e. pair behaviour was primarily feeding and they do not return following disturbance); 3 ) After a nest site was located, we selected a nearby hill and scanned the habitat using a Nikon ED $25 \times 60 \mathrm{~mm}$ telescope to locate the nest. After the nest was located, we then approached it and measured nest site parameters. Parameters were measured by the same persons throughout the three years to reduce data variability. Field survey dates were 5 May to 23 June in 2003, 18 May to 25 June in 2004, and early June 2005. We did not collect breeding success data.

Wang and Chen (2002) classified Black-necked Crane nests into five types: island, mud, reed, grassy island, and permanent. In RWNR, only island, mud and reed nests were found. Because mud and reed nests need to be repaired before and during incubation, while island and grassy island nests do not, we categorized reed and mud nests as energy consuming nests and island and grassy island nests as non-energy consuming nests. Nest site parameters that we measured included site factors and nest characteristics. Site factors were: elevation (m), habitat type (lake, swamp or river), distance to roads and buildings as categories (far: $>_{1,000} \mathrm{~m}$ and close: $<_{1}, 000 \mathrm{~m}$ ), and a disturbance category (high: livestock, humans or dogs can approach as close as $10-20 \mathrm{~m}$; or minor: livestock cannot approach the nest site due to a water barrier). Nest characteristics were: nest height (from water to top of nest platform in $\mathrm{cm}$ ), shortest distances to nearest water body and the mainland $(\mathrm{m})$, water body area (categorized as $<500 \mathrm{~m}^{2}$ or $>_{500 \mathrm{~m}^{2}}$ ), area of nest site $\left(\mathrm{m}^{2}\right)$, water depth near nest (in $\mathrm{cm}$, taken from direction closest to land), nest depth and width, mean grass height near nest (measured at four cardinal compass directions around nest), I $\mathrm{m}$ grass height near nest (measured at four cardinal compass directions $1 \mathrm{~m}$ from nest and considered an index of concealment), and a concealment category (open [nest visible by simple scan] vs. concealed [nest obscured by vegetation]).

\section{Data analysis}

Data on land use and habitat types were obtained from the Forestry Bureau of Ruoergai County. Ruoergai Wetland was composed of $86.2 \%$ grassland and $13.8 \%$ wetland, including lake $(1,233 \mathrm{ha})$, swamp (19,892 ha) and river ( 1,828 ha) habitats (Sichuan Forestry Survey and Planning Institute 1997). The proportions of wetland and grassland available in the landscape were calculated and used to calculate the selectivity index (S.I.: Ivelev 1962): S.I. $=\frac{(\mathrm{Ci}-\mathrm{Ai})}{(\mathrm{Ci}+\mathrm{Ai})^{\prime}}$ where $\mathrm{Ci}$ is the proportion of the nest number in $\mathrm{i}^{\text {th }}$ microhabitat out of the total available habitat; Ai is the proportion of the $\mathrm{i}^{\text {th }}$ microhabitat. The S.I. ranges between -1 and +1 . An S.I. $<-0.5$ indicates negative selection and S.I. $>+0.5$ indicates positive selection. If $-0.5 \leq$ S.I. $\geq+0.5$, this indicates that the utilization of the microhabitat is in proportion to its availability in the environment. For normal 
data, we used parametric analyses, and non-parametric analyses for non-normal data (Zar 1999). Nest parameters (nest length, width, height, and water depth near nest) among different microhabitats were examined using a one-way ANOVA test. Then an unpaired t-test was used to test for differences (I) between energy consumed and non-energy consumed nests and (2) among nests from lake, river and swamp areas. As both biotic and abiotic factors might be involved in the choice of nest sites and interactions among all examined traits might exist, we used Principal Components Analysis (PCA) to determine which variables were driving the trends we observed ( $\mathrm{O}^{\prime}$ Conner 1978, McGarigal et al. 2000). Pearson correlation was used to analyze the relationship between water depth and nest height in the different microhabitats (Zar 1999). All data were analyzed using SPSS 11 .0 software (Yu and He 2003). All probabilities quoted are two tailed. Means are given \pm SE.

\section{Results}

\section{The nest and nest site selection}

Black-necked Cranes at Ruoergai nested on elevated spots within wetland habitats. Their nest platforms were made up of grassy islands, aquatic vegetation and mud. Nest shape was trapezoidal, having a broad base submerged in water with a narrower crown. The top view of the nest above the water surface level was round or oblong. The centre of the nest was always slightly depressed. Throughout our study, 21 nests were found (three reed, four mud and 14 island nests). Nest parameters showed significant differences among different nest types $(P<0.05)$. Reed nests were largest and island nests were smallest. The parameters of energy-consumed nests were larger than those of non energy-consumed nests (nest length: $t=3.93, \mathrm{df}=19, P<0.001$; nest width: $t=5.40, \mathrm{df}=19 P<0.001$; nest height: $t=3.96, \mathrm{df}=19, P<0.001)$, except water depth near nest $(t=-1.13, \mathrm{df}=19, P>0.05)$ (Table 1 ).

The distribution of nests in RWNR was restricted to wetland habitat types. All 21 nests were found in wetland habitat, which occupies less than $14 \%$ of the total area. No nests were found in grassland habitats (more than $86 \%$ of the total area). Within the wetland, the pooled data of three years showed a significant difference in nest distribution $\left(\chi_{2}^{2}=10.6, P<0.01\right)$. A relatively higher number of nests were recorded in lake $(66.7 \%)$, than swamp and river habitats. Three reed nests, two mud, nests, and nine island nests were observed in lake habitats. Two mud nests and one island nest were found in river habitat. Only island nests (4) were found in swamp habitat. During our three year study, few nests were located in river sites $(0-1-2)$, while a decrease in the use of lake sites was found $(7-4-3)$, reaching its minimum (21.4\%) during the 2005 breeding season. However, the use of swamp was stable $(1-1-2)$. There was no annual variation in the distribution of nests in different microhabitats $\left(\chi_{2}^{2}=0.29, P>0.05\right)$. Ivelev's

Table 1. Traits of three nest types (mean \pm SE) of Black-necked Crane in Ruoergai Wetland Nature Reserve.

\begin{tabular}{lllll}
\hline Nest types & \multicolumn{3}{l}{ Variables $^{\mathrm{a}}$} \\
\cline { 2 - 5 } & Length $(\mathrm{cm})$ & Width $(\mathrm{cm})$ & Height $(\mathrm{cm})$ & Water depth near nest $(\mathrm{cm})$ \\
\hline Reed-nest $^{\mathrm{b}}$ & $75.7 \pm 2.3(3)$ & $58.3 \pm 3(3)$ & $32.5 \pm 0.7(9)$ & $29.5 \pm 2.5(3)$ \\
Mud-nest $^{\mathrm{b}}$ & $62.3 \pm 7.8(4)$ & $44 \pm 5.4(4)$ & $26.3 \pm 2(4)$ & $15.9 \pm 1.2(4)$ \\
Ground-nest $^{\mathrm{c}}$ & $50.6 \pm 1.9(14)$ & $31.1 \pm 1.4(14)$ & $23.5 \pm 0.5(14)$ & $33 \pm 2.4(14)$ \\
$\mathrm{F}$ & $10.80^{* * *}$ & $24.63^{* * *}$ & $18.34^{* * *}$ & $10.71^{* * *}$ \\
$\mathrm{t}$ & $3.93^{* * *}$ & $5.40^{* * *}$ & $3.96^{* * *}$ & $1.13^{\text {ns }}$ \\
\hline
\end{tabular}

a one way ANOVA with Independent t-test.

benergy-consumed nests

cnon energy-consumed nest.

${ }^{\mathrm{ns}}$ not significant; ${ }^{* * *} P<0.001$. 
selectivity index for nest site selection indicated that lake habitats were positively selected for nesting. Swamp was negatively selected for nesting, but river was selected in proportion to its availability during 2003 and 2005 (Table 2).

\section{Effect of microhabitat on nest size and water depth requirement}

Except for nest length $(P<0.05)$, there were no significant differences in nest width, nest height and water depth near nest in comparison to nests among different habitats. Nests in the lake habitat had the greatest length $(61.7 \mathrm{~cm})$ (Table 3). Water depth around the nest varied from $23 \mathrm{~cm}$ to $48 \mathrm{~cm}$, with an average of $31.1 \pm 2.4 \mathrm{~cm}(n=21)$. No significant correlations were established between water depth and nest height $(r=+0.36, \mathrm{df}=21, P=0.115)$. This held true in lake $(r=0.49, \mathrm{df}=14, P=0.075)$, swamp $(r=-0.26, \mathrm{df}=4, P=0.74)$, and river habitats $(r=-0.52, \mathrm{df}=3, P=0.66)$.

\section{Characteristics of nest sites}

Of the habitat traits in Table 3, principal component 1 (PCI) appeared to account for $33.3 \%$ of the variance in eight traits, whereas $\mathrm{PC}_{2}$ accounted for $23.4 \%$ and $\mathrm{PC}_{3}$ for $19.1 \%$. The area of water body exhibited the highest influence in PCI with $66.7 \%$ of nests sited in water bodies $>500 \mathrm{~m}^{2}$. Water depth near nests (31.1 $\pm 2.4 \mathrm{~cm}, n=21$ ) was highly correlated with PC2, and the grass height $(12.7 \pm 2.1 \mathrm{~cm}, n=21)$, and $1 \mathrm{~m}$ grass height near nest $(16.6 \pm 5.6 \mathrm{~cm}, n=21)$ were most strongly associated with $\mathrm{PC}_{3}$ (Table 4 ).

\section{Comparison with minor disturbed areas}

Compared with nests found in Qinghai, Tibet and Ladakh, nest parameters in Ruoergai Wetland were significantly different $(P<0.05)$. Nests in Ruoergai Wetland were smaller (nest length: $56.4 \pm 2.7 \mathrm{~cm}$; nest width: $37.5 \pm 2.6 \mathrm{~cm})$, but average water depth around nest was deeper $(31.1 \mathrm{~cm}$ vs. $18.2 \mathrm{~cm})$. No significant difference was found in nest height among these areas $(P>0.05)$.

\section{Discussion}

Previous studies on the breeding ecology of the species include some broad descriptive information, such as nest environment ( $\mathrm{Li}$ 1987), nesting areas and nest (Dwyer et al. 1992). In the present study, we gave the first detailed statistics on nest site selection and found that water body area, water depth near nest, grass height around and beside nests are important factors affecting nest site selection in Ruoergai Wetland. Preferred nest sites by Black-necked Cranes were associated with large water bodies $\left(>_{500} \mathrm{~m}^{2}\right)$, a certain water depth (average $31.1 \mathrm{~cm}$ ), and a certain height of wetland vegetation. Larger water bodies and a greater distance to land

Table 2. Nest site selection by black-necked crane in Ruoergai Wetland Nature Reserve.

\begin{tabular}{|c|c|c|c|c|c|c|c|c|c|c|c|c|}
\hline \multirow[t]{3}{*}{ Microhabitat } & \multicolumn{12}{|c|}{ Study year } \\
\hline & \multicolumn{3}{|l|}{2003} & \multicolumn{3}{|l|}{2004} & \multicolumn{3}{|l|}{2005} & \multicolumn{3}{|c|}{$2003-2005$} \\
\hline & River & Swamp & Lake & River & Swamp & Lake & River & Swamp & Lake & River & Swamp & Lake \\
\hline Availability & 0.079 & 0.867 & 0.054 & 0.079 & 0.867 & 0.054 & 0.079 & 0.867 & 0.054 & 0.079 & 0.867 & 0.054 \\
\hline Nest observed & $\mathrm{O}$ & 1 & 7 & 1 & $I$ & 4 & 2 & 2 & 3 & 3 & 4 & 14 \\
\hline Nest expected & 0.6 & 6.9 & 0.5 & 0.5 & 5.2 & 0.3 & 0.6 & 6.1 & 0.3 & 1.7 & 18.2 & 1.1 \\
\hline$\chi^{2}$ value & & & & & & & & & & $10.57^{* * *}$ & & \\
\hline $\begin{array}{l}\text { Selectivity } \\
\text { index }\end{array}$ & & -0.75 & +0.88 & +0.36 & -0.68 & +0.51 & +0.70 & -0.50 & +0.78 & +0.29 & -0.64 & +0.85 \\
\hline
\end{tabular}

$* * * P<0.001$ 
Table 3. Nest parameters and nest site characteristics among different microhabitats of Black-necked Crane in Ruoergai Wetland.

\begin{tabular}{|c|c|c|c|c|c|c|}
\hline & \multirow[t]{2}{*}{ Variables } & \multicolumn{5}{|l|}{ Microhabitats $^{\mathrm{a}}$} \\
\hline & & Lake $^{b}$ & Swamp ${ }^{c}$ & River $^{\mathrm{d}}$ & $\mathrm{F}$ & $P$ \\
\hline \multirow[t]{3}{*}{ Nest } & Length $(\mathrm{cm})$ & $61.7 \pm .2(14)^{*}$ & $44.5 \pm 2.1(4)^{\mathrm{ns}}$ & $47 \cdot 3 \pm 3.7(3)^{\mathrm{ns}}$ & 5.559 & $0.013^{*}$ \\
\hline & Width $(\mathrm{cm})$ & $40.8 \pm 3.6(14)$ & $31.3 \pm 1(4)$ & $30.3 \pm 0.9(3)$ & 1.79 & $0.195^{\mathrm{ns}}$ \\
\hline & Height $(\mathrm{cm})$ & $25 \cdot 3 \pm 1.2(14)$ & $24.2 \pm 0.8(4)$ & $26.9 \pm 1.2(3)$ & 0.408 & $0.671^{\mathrm{ns}}$ \\
\hline \multirow[t]{6}{*}{ Nest site } & $\begin{array}{l}\text { Water depth near } \\
\text { nest }(\mathrm{cm})\end{array}$ & $30.4 \pm 2.7(14)$ & $33.7 \pm 3.2(4)$ & $30.7 \pm 13.2(3)$ & 0.121 & $0.887^{\mathrm{ns}}$ \\
\hline & Distance to water (m) & $1.4 \pm 0.5(14)$ & $0.4 \pm 0.02(4)$ & $0.2 \pm 0.1(3)$ & 0.943 & $0.408^{\text {ns }}$ \\
\hline & Distance to mainland (m) & $35 \cdot 7 \pm 7.6(14)$ & $3 \pm 0.4(4)$ & $3.3 \pm 0.3(3)$ & 4.263 & $0.03^{\text {ns }}$ \\
\hline & $\begin{array}{l}\text { Grass height near } \\
\text { nest }(\mathrm{cm})\end{array}$ & $11.2 \pm 2.7(14)$ & $16.8 \pm 2.6(4)$ & $14.7 \pm 7.5(3)$ & 0.562 & $0.58^{\text {ns }}$ \\
\hline & $\begin{array}{l}\text { I } \mathrm{m} \text { Grass height near } \\
\text { nest }(\mathrm{cm})\end{array}$ & $22.9 \pm 7 \cdot 7(14)$ & $\mathrm{O}(4)$ & $9.4 \pm 9.4(3)$ & 1.438 & $0.263^{\mathrm{ns}}$ \\
\hline & Area of nest site $\left(\mathrm{m}^{2}\right)$ & $8.8 \pm 3.6(14)$ & $1.2 \pm 0.03(4)$ & $3.1 \pm 2(3)$ & 0.837 & $0.449^{\text {ns }}$ \\
\hline
\end{tabular}

a one way ANOVA.

${ }^{\mathrm{b}}$ Independent samples t-test; Lake vs Swamp.

'Independent samples t-test; Swamp vs River.

${ }^{\mathrm{d}}$ Independent samples t-test; Lake vs River.

${ }^{\mathrm{ns}}$ not significant; ${ }^{*} \mathrm{P}<0.05$.

( $>$ 10 $\mathrm{m}$ ) are likely to prevent land predators from accessing nests, while deeper water near nest sites was also likely selected to reduce losses to nest predators. Water depths and nest materials selected by cranes may be due to experience with flood risk. However, in Ruoergai Wetland, water levels are stable. Water depth around the nest averaged $31.1 \mathrm{~cm}$, which indicates the minimum physical requirement to create a nesting environment. Predator community composition might also affect nest habitat preference and selection. In Ruoergai Wetland, predators such as Red Fox, Grey Wolf Canis lupus and dogs are common. That is probably why we found no difference in water depth near nests in different microhabitats that are likely to have different predation risk. Large water bodies may also be preferred as nest sites because they support taller wetland vegetation, which provides better nest concealment.

All nests were in wetland habitat and no nests were found in much more abundant $(86 \%)$ grassland habitat, which highlights the importance of wetland habitats for breeding. Selection of wetland for nesting sites has also been found in Sandhill Crane G. canadensis (Walkinshaw 1973a), Sarus Crane (Board et al. 2001) and Whooping Crane G. americana (Kuyt 1995).

Table 4. Principal component loadings through a rotation method for eight traits of nest site selection by black-necked crane in Ruoergai Wetland Nature Reserve, Sichuan, China.

\begin{tabular}{lccc}
\hline Variables & PCI & PCII & PCIII \\
\hline Elevation & $-8.58 \mathrm{E}-02$ & 0.74 & 0.359 \\
Distance to water & 0.412 & $-3.07 \mathrm{E}-\mathrm{O2}$ & 0.653 \\
Distance to land & 0.72 & 0.459 & $-2.34 \mathrm{E}-\mathrm{O} 2$ \\
Water depth & $7.21 \mathrm{E}-02$ & 0.879 & $-3.68 \mathrm{E}-\mathrm{O} 2$ \\
Grass height near nest & $-4.56 \mathrm{E}-02$ & 0.281 & 0.867 \\
Grass height I m near nest & 0.546 & 0.461 & -0.539 \\
Water body area & 0.923 & -0.264 & $-6.39 \mathrm{E}-\mathrm{O} 2$ \\
Disturbance & -0.779 & $-5.46 \mathrm{E}-\mathrm{O} 2$ & -0.328 \\
Eigenvalue & 2.67 & 1.87 & 1.53 \\
$\%$ of total variance & 33.3 & 23.4 & 19.1 \\
\% of cumulative variance & 33.3 & 56.7 & 75.9 \\
\hline
\end{tabular}


Table 5. Nest parameters (mean $\pm \mathrm{SE}$ ) in Ruoergai Wetland Nature Reserve and in other regions in Qinghai-Tibet Plateau.

\begin{tabular}{lllllllr}
\hline Nest & Ruoergai Wetland & $n$ & Other regions & $n$ & $T$ & $n$ & $P$ \\
\hline Length $(\mathrm{cm})$ & $56.4 \pm 2.7$ & 21 & $77.1 \pm 5.2$ & 25 & 3.31 & 44 & 0.002 \\
Width $(\mathrm{cm})$ & $37.5 \pm 2.6$ & 21 & $67.1 \pm 5$ & 25 & 4.98 & 44 & $<0.001$ \\
Height $(\mathrm{cm})$ & $25.3 \pm 0.8$ & 21 & $23.2 \pm 4.8$ & 25 & -0.40 & 44 & 0.694 \\
Water depth $(\mathrm{cm})$ & $31.1 \pm 2.4$ & 21 & $18.2 \pm 2.5$ & 24 & 3.63 & 43 & 0.001 \\
\hline
\end{tabular}

Though wetland generally is favoured for breeding by Black-necked Cranes, they showed preferences for certain microhabitats. The reason that most nests $(66.7 \%)$ occurred in lake habitats might be due to selection of less disturbed areas with a lower probability of predation. But lake areas only occupied $5.4 \%$ of the wetland habitats, and are currently declining (Sichuan Forestry Survey and Planning Institute 1997) which suggests the urgency of protection for existing lake habitats.

Swamp areas comprised the largest proportion $(86.7 \%)$ of wetland habitat, but very few nests were found there. High disturbance and predation probability caused by water level decline might be the main reasons. All four nests in swamp habitat were in $<100 \mathrm{~m}^{2}$ areas. The importance of small water bodies in nest site selection has also been found in Sarus Crane in India (Borad et al. 2001). Gromadzki (1995) pointed out that only a small proportion of the crane population can be saved in legally protected areas and general protection measures must be taken for the protection of smaller breeding sites. In swamp area of Ruoergai Wetland, those small water bodies serve as a buffer area for breeding cranes. In previous studies, no nests were found in river areas, indicating that this habitat might not be appropriate for breeding Black-necked Cranes (Walkinshaw 1973a). However, we found nests in river habitat at Ruoergai Wetland, suggesting a possible response to a decline in suitable breeding habitat. Nests in such unsuitable habitat might face higher destruction rate $(40 \%)$. Though no nests were found in meadow areas, we should not ignore the importance of this habitat as the primary feeding site for breeding cranes. At present, road building and fencing has caused fragmentation of these meadow feeding areas. The presences of roads or power lines have made suitable marshes less likely to support groundnesting birds in the UK (Milsom et al. 200o). Road effects on wildlife also include reduction in the quality of habitat for forest or grassland birds through noise production or visual disturbance (Forman and Alexander 1998). Road effects, pollution, noise and fencing might have negative effects on feeding cranes.

Crane nest size has been reported to be influenced by different microhabitats (Walkinshaw 1973 b), but we did not document this trend in our study in the Ruoergai Wetland. Except for the nest length, nest sizes in different microhabitat were similar. Because three reed-nests were found in lakes, and these nests needed to be repaired before and during incubation, the nest length in this habitat was largest. Nest height may be related to maintaining a certain moisture regime for the eggs. They need to be very slightly moist or humid, but not too wet. Lower nests might cause eggs to be too moist and result in hypothermia and embryo death. Nest height above the water surface was similar among different microhabitats, suggesting that the cranes maintained a constant distance between eggs and water surface. A certain nest height above the ground surface may have helped incubating Black-necked Crane in maintaining vigilance against intruders.

Compared with nests found in Qinghai province, Tibet and Ladakh, nests in Ruoergai Wetland were smaller, but water depth near nest was deeper. Disturbance, vegetation type and climate might be the main reasons for these differences. For example, in Longbaotan Wetland, Qinghai, nest sites were in wetlands where water levels were affected by snow thaw. Due to water level fluctuations in that area, breeding Black-necked Cranes have to repair nests and thus form bigger nests (Li and Ma 1989). 


\section{Management considerations}

All nests occurred in wetland habitat, highlighting the importance of wetlands to the conservation of the species. At present, management should focus on lake and swamp restoration. Building activities should be restricted as few as possible and cars should not be allowed to approach the lakeshores during the nesting season. Ditch digging activities should be outlawed in swamp habitat, and wetland restoration should be pursued. Some regions should be designated as non-grazing areas during critical nesting periods (May and June). Long-term goals should include dam building in ditches in swamp areas to increase water levels and expand suitable breeding habitat for the birds. Also, the importance of meadow habitat as the primary feeding site should be addressed. Overgrazing has compressed the activity areas of breeding families (Yang et al. 2007) and degraded meadow vegetation conditions. We suggest controlling livestock in the grassland during specific periods (May to August) and creating several buffer zones near lake and swamp areas that forbid livestock grazing.

\section{Acknowledgements}

Financial support for the study was provided by a grant from the Chinese Academy of Sciences (KSCX2-SW-119), Western light foundation of Chinese Academy of Sciences, and the International Crane Foundation. We are grateful to Dr. Li Fengshan, Beth Lorence, Nishara Somasundaram, Mary Anne Bishop and Anne Lacy for valuable comments on earlier drafts of the manuscript. We thank Fu Qishan, Ren Shupei, Na Ke, Cai Ben and Xi La for assistance in the field.

\section{References}

Archibald, G. W. and Oesting, M. (1981) Black-necked Crane: a review. Pp. 190196 in J. C. Lewis and H. Masatomi, eds. Crane research around the world. Baraboo, Wisconsin: International Crane Foundation.

Birdlife International. (2001) Threatened birds of Asia: the BirdLife International red data book. Cambridge, UK: BirdLife International.

BirdLife International (2008) Species factsheet: Grus nigricollis. Downloaded from http://www.birdlife.org on 10/12/2008.

Bishop, M. A. (1996) Black-necked Crane (Grus nigricollis). Pp. 184-194 in C. D. Meine and G. W. Archibald, eds. The cranes: status survey and conservation action plan. Gland, Switzerland: IUCN.

Bock, C. E. (1997) The role of ornithology in conservation of the American West. Condor 99: $1-6$.

Borad, C. K., Mukjerjee, A. and Parasharya, B. M. (2001) Nest site selection by the Indian Sarus Crane in the paddy crop agroecosystem. Biol. Conserv. 98: 89-96.
Caughley, G. (1994) Directions in conservation biology. J. Anim. Ecol. 63: 215-244.

Dolan, B. (1939) Zoological results of the second Dolan expedition to western China and eastern Tibet, 1934-36. Part I. Proc. Ac. Nat. Sci. Philadelphia 90: 159-185.

Dresser, H. E. (1906) On some Palaearctic birds eggs from Tibet. Ibis 6: 337 .

Dwyer, N. C., Bishop, M. A., Harkness, M. A. and Zhang, Y. Z. (1992) Black-necked Cranes nesting in the Tibet Autonomous Region, P. R. China. North American Crane Workshop 6: 75-80.

Forman, R. T. and Alexander, L. E. (1998) Roads and their major ecological effects. Annu. Rev. Ecol. Syst. 29: 207-231.

Gromadzki, M. 1995. Conservation prospects of cranes in Poland. Pp. 451-452 in H. Prange, ed. Crane research and protection in Europe. Halle-Wittenberg, Germany: European Crane Working Group/Martin Luther-Universitat.

Ivelev, V. S. (1962) Experimental ecology of the feeding fishes. New Haven, CT: Yale University Press. 
Kuyt, E. (1995) The nest and eggs of the Whooping Crane, Grus Americana. Can. Field Nat. 109: 1-5.

Li, D. H. (1987) The distribution and status of the Black-necked crane on the Tibetan Plateau. Proc. 1983 Intl. Crane Workshop: 45-49.

Li, D. H. and Zhou, Z. J. (1985) Observation on the population behavior of the Blacknecked Crane during brooding on the Longbaotan in Qinghai province. Chinese Wildlife 6: 4-9.

Li, F. S. and Yang, F. (2003) Population numbers and distribution of Black-necked Crane (Grus nigricollis) in the Yungui Gaoyuan Plateau. Chi. J. Zool. 38: 43-46.

Li, L. X. (1996) Preliminary exploration on the building and formation of breeding Black-necked crane territory. Pp. $272-276$ in R. D. Zeng, ed. Wetland conservation and rational use - Chinese wetland conservation corpus. Beijing: Chinese Forestry Publishing House.

McGarigal, K., Cushman, S. and Stafford, S. (2000) Multivariate statistics for wildlife and ecology research. New York: Springer Verlag.

McNamee, P. (2003) Management plan for Ruoergai national nature reserve. Report to GEF/UNDP-PR/98G32 Wetland biodiversity conservation and sustainable use in China.

Meine, C. D. and Archibald, G. W. (1996) The cranes: status survey and conservation action plan. Gland, Switzerland and Cambridge, UK: IUCN.

Milsom, T. P., Langton, S. D., Parkin, W. K., Peel, S., Bishop, J. D., Hart, J. D. and Moore, N. P. (200o) Habitat models of bird species' distribution: an aid to the management of coastal grazing marshes. J. Appl. Ecol. 37: 706-727.

O'Conner, R. J. (1978) Structure in avian growth patterns: a multivariate study of passerine development. J. Zool. 185: 147-172.

Pfister, O. (1998) The breeding ecology and conservation of the Black-necked Crane (Grus nigricollis) in Ladakh, India. MSc. thesis. Hull, UK: University of Hull.

Scott, D. A. (1993) The Black-necked Cranes Grus nigricollis of Ruoergai Marshes,
Sichuan, China. Bird Conserv. Internatn. 3: 245-259.

Sichuan Forestry Survey and Planning Institute. (1997) Survey report of Xiaman Nature Reserve of Sichuan Province. Chengdu: Sichuan Forestry Survey and Planning Institute.

Stone, W. (1933) Zoological results of the Dolan west China expedition of 1931. Part I. Birds. Proc. Ac. Nat. Sci. Philadelphia 85: 165-222.

UNEP-WCMC. (2003) Checklist of birds listed in the CITES Appendices and in EC Regulation No. 338/97. 7 th ed. Peterborough, UK: JNCC.

Vaurie, C. (1972) Tibet and its birds. London: H.F. and G. Witherby Limited.

Walkinshaw, L. H. (1973a) Cranes of the world. New York: Winchester Press.

Walkinshaw, L. H. (1973b) A history of Sandhill Crane on the Haehnle Sanctuary, Michigan. Jack-Pine Warbler 51: 54-74.

Wang, Y. H. and Chen, E. L. (2002) The Black-necked Cranes in China. Guiyang: Guizhou Renming Publishing House.

Willson, M. F. and Gende, S. M. (200o) Nesting success of forest birds in southeast Alaska and adjacent Canada. Condor 102: 314-324.

Wu, Z. K., Li, Z. M., Wang, Y. H., Jiang, Y. M., Li, R. X., Li, D. H., Zhou, Z. J. and Li, L. X. (1993) Migration of Black-necked Cranes in China. Acta Zool. Sinica 39: 105-106.

Yan, Z. L. and Wu, N. (2005) Rangeland privatization and its impacts on the Zoige Wetlands on the Eastern Tibetan Plateau. J. Mount. Sci. 2: 105-115.

Yang, R., Wu, H. Q., Yang, X. J., Jiang, W. G., Zuo, L. and Xiang, L. (2007) Diurnal time budget of the Black-necked Crane during the breeding season. Waterbirds 30: 80-85.

Yang, X. J., Qian, F. W., Li, F. S., Gao, L. B. and $\mathrm{Wu}, \mathrm{H}$. Q. (2005) First satellite tracking of Black-necked Cranes in China. Zool. Res. 26: 657-658.

$\mathrm{Yu}$, J. Y. and He, X. H. (2003) Statistics and analysis for data and the application of SPSS. Beijing: Post \& Telecommunications Press.

Zar, J. H. (1999) Biostatistical analysis. 4th edition. New Jersey, USA: Prentice-Hall. 
HEQI WU, XIAOJUN YANG*

State Key Laboratory of Genetic Resources and Evolution, Kunming Institute of Zoology, Chinese Academy of Sciences, Kunming, Yunnan 650223, P. R. China.

Current address: Graduate School of the Chinese Academy of Sciences, Beijing, 100039, P. R. China.

KE ZHA, MING ZHANG

Ruoergai Wetland Management Bureau, Ruoergai, Sichuan 62450o, P. R. China.

${ }^{*}$ Corresponding author; e-mail: yangxj@mail.kiz.ac.cn

Received 24 March 2008; revision accepted 15 October 2008 